
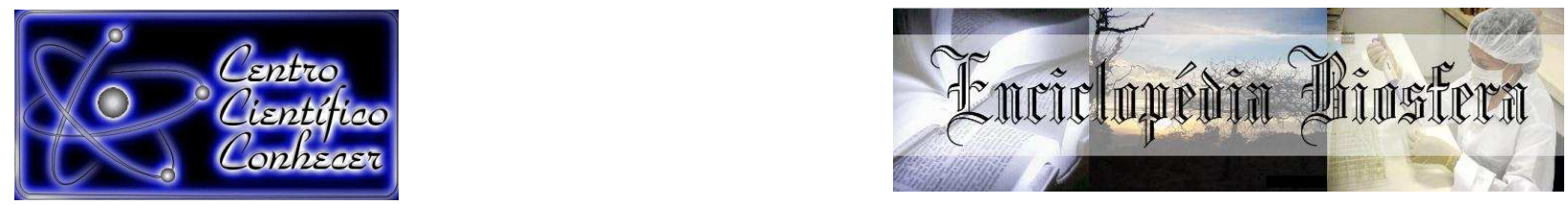

\title{
IDENTIFICAÇÃO BOTÂNICA COMO FERRAMENTA PARA EDUCAÇÃO AMBIENTAL NAS TRILHAS INTERPRETATIVAS
}

Pollyanne de Paula Pereira ${ }^{1}$, Luanna Elis Guimarães², Flaviana Delmiro Oliveira $^{3}$, Thalles Oliveira Martins ${ }^{4}$, Carlos de Melo e Silva Neto ${ }^{5}$

1. Graduada em Biologia, Instituto Federal Goiano - Câmpus Ceres. Ceres, Goiás, Brasil. E-mail: pollyanne_pereira@outlook.com

2. Especialista. Mestre em Agronomia, Universidade Federal de Goiás, Goiânia, Brasil.

3. Mestranda em Agronomia, Universidade Federal de Goiás, Goiânia, Brasil

4. Mestrando em Ciências Florestais, Universidade de Brasília, Brasília, Brasil.

5. Doutorando em Agronomia, Universidade Federal de Goiás, Goiânia, Brasil.

Recebido em: 08/09/2015 - Aprovado em: 14/11/2015 - Publicado em: 01/12/2015 DOI: http://dx.doi.org/10.18677/Enciclopedia_Biosfera_2015_019

\begin{abstract}
RESUMO
As trilhas ecológicas do Instituto Federal Goiano - Câmpus Ceres existem com um caráter educativo e podem ser definidas como um percurso em sitio natural que consegue promover um contato mais estreito entre o ser humano e a natureza. Valendo-se disso, o objetivo principal foi de fazer a identificação botânica das espécies arbórea ao longo do percurso das Trilhas Curumim e Ver o Rio e utilizar esse levantamento como ferramenta pedagógica no ensino de Educação Ambiental. As duas áreas de estudo (Trilha Curumim e a Ver o Rio) estão localizadas dentro da Área de Preservação Permanente (APP), do IF Goiano - Câmpus Ceres. Com a ajuda da Equipe PROFLORESTA-UFG, foram realizadas visitas de campo onde foi possível a identificação de cinco fitofisionomias predominantes das áreas de estudo e de 60 espécies arbóreas dentre elas, 51 gêneros, representadas em 29 famílias.
\end{abstract}

PALAVRAS - CHAVE: Cerrado. Ecoturismo. Educação Sustentável. Levantamento Fitofisionômico.

\section{BOTANICAL IDENTIFICATION AS A TOOL FOR ENVIRONMENTAL EDUCATION ON THE TRACKS INTERPRETATIVE}

\begin{abstract}
The nature trails of the Federal Institute Goiano - Campus Ceres have a pedagogical porpuse, beeing defined as a course in a natural site that can promote closer contact between man and nature. Taking advantage of this, the aimed to make the botanical identification of tree species along the Curumim trail and River View trail, using this survey as a pedagogical tool in teaching environmental education. The two study areas are located within the Permanent Preservation Area (APP), the IF Goiano - Campus Ceres, the Curumim and the River View trails. With the help of PROFLORESTA-UFG team, field visits took place where it was possible identifying
\end{abstract}


five predominant vegetation types of the study area and 60 tree species, among them 51 genera, represented in 29 families.

KEYWORDS: Cerrado. Ecotourism. Sustainable Education. Vegetational survey.

\section{INTRODUÇÃO}

O Cerrado é um dos biomas terrestres de maior endemismo e diversidade de espécies. Estimava-se que nesta região haviam 10 mil espécies de plantas, das quais aproximadamente 4.400 são endêmicas (OLIVEIRA - FILHO \& RATTER, 2002; CARDOSO et al., 2009). Para RESENDE (2012), o Cerrado Brasileiro destaca-se como o segundo maior bioma do Brasil, sendo considerado como a savana mais diversificada do mundo. Apresenta um complexo mosaico de fitofisionomias que vão desde áreas savânicas até áreas florestais, com alta riqueza de espécies e grande número de endemismos. O Planalto Central é, também, uma região de nascentes e extensa área de recarga de seis das oito grandes bacias hidrográficas brasileiras.

Estudos como os levantamentos florísticos, fitossociológicos e identificação botânica têm fornecido informações importantes para a compreensão dos padrões biogeográficos do cerrado, e subsidiado a determinação de áreas prioritárias para a conservação. Nestas circunstâncias CAMPANHA \& SILVA (2013), afirmam que as Unidades de Conservação são locais favoráveis para práticas de Educação Ambiental de caráter não formal. São nesses locais que as pessoas, de maioria residente no ambiente urbano, podem entrar em contato com o ambiente natural, e adquirirem informações, através dos meios interpretativos utilizados, sobre as interações que ocorrem no ambiente natural e relações existentes entre sociedade e natureza.

MENGHINI (2005), defende que a trilha é considerada interpretativa, quando seus recursos são traduzidos para os visitantes, com bases em temas pré-definidos através de folhetos, placas, painéis e mapas que relacionam o ecossistema ali presente com conteúdo dirigido pelos guias durante o processo de visitação. Toda essa infraestrutura torna as trilhas interpretativas, as quais podem ser usadas como importantes ferramentas educacionais.

CAMPOS \& FILLETO (2011), reconhecem que tanto para o ensino formal quanto para o não formal, as trilhas ecológicas constituem excelentes espaços para a prática de programas de educação ambiental, ecologia e botânica. Aos quais podem ir além de simplesmente ensinar o que os visitantes devem fazer nos ambientes visitados, mas também propor mudanças no modo como às pessoas pensam e avaliam a relação com o ambiente.

A educação constitui-se na mais poderosa de todas as ferramentas de intervenção no mundo para a construção de novos conceitos e consequente mudança de hábitos. É também o instrumento de construção do conhecimento e a forma com que todo o desenvolvimento intelectual conquistado é passado de uma geração a outra, permitindo, assim, a máxima comprovada de cada geração que avança um passo em relação à anterior no campo do conhecimento científico e geral (CUBA, 2010).

As trilhas ecológicas do Instituto Federal Goiano - Câmpus Ceres foram criadas com o intuito de promover um trabalho de Educação Ambiental não formal, e com isso estimular a recuperação de uma área degradada por meio do Projeto Módulo Demonstrativo de Recuperação do Cerrado dentro da Reserva Legal da então Escola Agrotécnica Federal de Ceres (EAFC), servindo posteriormente, como 
demonstrativo na criação de corredores ecológicos, interligando as Reservas Legais e as Áreas de Preservação Permanente - APP's. Ao mesmo tempo busca a integralização entre homem e natureza, a qual hoje é uma grande ferramenta para pesquisas e aulas práticas da Instituição, fomentando assim métodos de Educação e Preservação Ambiental, Ecologia, Inclusão Social e Acessibilidade.

A partir destes conceitos objetivou-se neste trabalho a identificação botânica das espécies de maior representação ecológica e social nas Trilhas Ver o Rio e Curumim, com o intuito de fomentar o uso das espécies como um atrativo pedagógico na realização de práticas educativas em espaços não formais para o conhecimento da biodiversidade do Cerrado.

\section{MATERIAL E MÉTODOS}

\section{Área de Estudo}

A área de estudo está localizada dentro da Área de Preservação Ambiental (APP), do Instituto Federal Goiano - Câmpus Ceres, localizado na Go - 154, Km 03, Zona Rural, Ceres - GO, situado na Região do Vale de São Patrício, médio norte goiano.

O clima da região é classificado como tropical subúmido com temperaturas de $2^{\circ} \mathrm{C}$, relevo plano ondulado, o solo é do tipo latos solo vermelho amarelo. A agricultura predominante da região é a cana de açúcar, ressaltando também a agropecuária.

A APP possui uma área que corresponde a 1 ha (hectare), onde estão localizadas duas áreas de estudo a Trilha Curumim, que possui 230 metros, a Trilha Ver o Rio que possui 1300 metros e a parcela do Módulo Demonstrativo do Cerrado (MDR). A trilha Curumim, por ter um percurso mais curto, é utilizada em especial com atividades voltadas as aulas de Ciências para o ensino fundamental de escolas do município de Ceres, e também da região do Vale do São Patrício.

Ao lado da Trilha Curumim está a trilha Ver o Rio, que possui 1300 metros de extensão e é banhada por dois importantes cursos d'águas: Córrego Azul e Rio Verde. Nessa trilha os visitantes são instigados a observarem a importância de uma APP, e os encontros dos cursos d'água existentes. Essa trilha possui ainda, particularidades transicionais com diferentes características e grande potencial de utilização para diversas áreas de estudo. Esse local é bastante utilizado para trabalhos de educação ambiental com visitantes de outras Instituições e pelos alunos do IF Goiano - Câmpus Ceres, com o intuito de realizar aulas práticas nas disciplinas de Ecologia, Sistemática e Organografia Vegetal, Manejo e Conservação da Biodiversidade, Biogeografia, Educação Ambiental entre outras, demonstrando assim o potencial que a área tem de ser usada como um espaço formal e não formal de aprendizagem.

Os Módulos Demonstrativos de Recuperação de Áreas Degradadas com espécies nativas de uso múltiplo - MDR, consistem em unidades de plantio misto em que são utilizadas espécies nativas do Cerrado de uso múltiplo, trazendo, também, o benefício gerado pelas espécies utilizadas (OLIVEIRA, 2009).

\section{Funções das Fitofisionomias}

Foi realizado o levantamento das fitofisionomias presente na área de estudo para facilitar a descrição das espécies presente em cada ambiente seguindo a classificação de RIBEIRO \& WALTER (2008). O estudo foi realizado com base na arquitetura das árvores e na composição florística local. 


\section{Levantamento e Demarcação das Árvores Nativas}

O estudo se baseou na identificação das espécies arbóreas nativas com importância ecológica e econômica ao longo do percurso das duas trilhas interpretativas.

As árvores foram selecionadas e marcadas com plaquetas de alumínio, contendo um número específico para cada espécie, para facilitar a identificação e catalogação das mesmas. Toda área foi dividida em três parcelas para facilitar a marcação sendo elas a Trilha Curumim, Trilha Ver o Rio e parcela do MDR Módulo Demonstrativo de Recuperação do Cerrado. Com o auxílio de bibliografias especificas para essa prática, como SILVA JUNIOR (2005; 2009) e LORENZI (1992; 1998; 2009). Foi elaborada uma tabela com a seguinte descrição: o nome popular, nome científico das espécies, família botânica e numeração contidas nas placas de identificação.

A metodologia utilizada para o levantamento florístico foi o caminhamento, adaptada de FILGUEIRAS et al. (1994). As espécies foram registradas com câmera fotográfica, tiveram o material botânico (vegetativo, e reprodutivo quando encontrado) coletado com auxilio de tesoura de poda e obtiveram as coordenadas geográficas marcadas com GPS Garmin. O material botânico foi identificado com auxílio de chaves de identificação botânica (BARROSO et al., 1991) e também comparado com material botânico do Herbário da Universidade Federal de Goiás (UFG).

Para avaliação descritiva das espécies, foi realizada abundância absoluta para o conjunto das espécies. Para destacar as principais famílias botânicas foi realizado gráfico de barra de acordo com o número de espécies por família botânica, Metodologia adaptada de SILVA \& SANTOS, (2005)..

\section{RESULTADOS E DISCUSSÃO}

As fitofisionomias encontradas na área de estudo foram as seguintes: Mata Ciliar, Mata de Galeria, Floresta Estacional, Cerrado Stricto Sensu (sentido restrito) e Cerradão segue abaixo a descrição de cada conforme foi observado in loco:

- Mata ciliar - É representada pela vegetação encontrada as margens do Rio Verde, que tem em média $15 \mathrm{~m}$ de largura. A vegetação tem um porte arbóreo e não forma galerias. Entre as espécies encontradas nessa fitofisionomia, destacamse Ingá de Metro (Ingá vera) e Sangra d'água (Croton urucurana).

- Mata de galeria - É formada por árvores que tem a cobertura arbórea quase que total e com espécies emergentes ao dossel que atinge de 20 a $25 \mathrm{~m}$ de altura. Dentre as espécies presentes nessa fitofisionomia se sobressaem Jequitibá (Cariniana estrellensis) e Escova de Macaco (Apeiba tibourbou).

- Floresta Estacional - A floresta estacional encontrada nessa área é do tipo Mata Seca Decídua, que contribui para o aporte de matéria orgânica no solo. É a fitofisionomia de maior ocorrência na área de estudo e tem como representantes arbóreos o Mandiocão (Schefflera macrocarpa), a Pindaíba (Xylopia emarginata) e o Carvoeiro (Tachigali vulgaris).

- Cerrado Stricto Sensu (sentido restrito) - Na área de estudo essa vegetação se expressa através de árvores baixas, tortuosas com estrato herbáceosubarbustivo. Representando essa fitofisionomia se destacam as espécies CegaMachado (Physocalymma scaberrimum), Cajueiro (Anacardium sp.) e Muricizeiro (Byrsonima sericea). 
- Cerradão - É a área de menos representatividade, possui vegetação espaça, com cobertura arbórea em torno de $70 \%$ e as árvores possuem em média 7 $\mathrm{m}$ de altura e tem como principais representantes a Mutamba (Guazuma ulmifolia) e o Jatobá (Hymenaea courbari).

$\mathrm{Na}$ Trilha Curumim foi observada uma particularidade no Cerrado Central do Brasil. Essa área tem uma característica de área de transição da Mata Atlântica com o Cerrado. A área, portanto, pode ser considerada uma área de transição de fitofisionomia do Cerrado, ou seja, áreas de transição ambiental, onde comunidades ecológicas diferentes entram em contato.

O grande número de fitofisionomias encontradas na área demonstra as alterações que a vegetação sofre ao longo do tempo em um mesmo local, devido à frequência e intensidade de impactos como o fogo e o pastoreio e que se configura como um desafio na classificação do cerrado conforme descreve DURIGAN et al., (2002) e RIBEIRO \& WALTER (2008).

Para OLIVEIRA-FILHO \& RATTER (2002), a principal complicação para essa classificação se deve ao fato de que qualquer categoria dentro de uma classificação fisionômica da vegetação do cerrado é, na verdade, um segmento de uma série vegetacional contínua.

Em todas áreas, foi amostrado um total de 75 indivíduos em três fragmentos, sendo: 14 no 1ํ Fragmento que corresponde a Trilha Curumim, 41 no $2^{\circ}$ Fragmento que corresponde a Trilha Ver o Rio e 20 no $3^{\circ}$ Fragmento que corresponde ao MDR. Sendo o $2^{\circ}$ fragmento o que apresentou maior número de indivíduos. A maior riqueza florística foi encontrada no $2^{\circ}$ Fragm ento, com 41 espécies levantadas (Quadro 1).

QUADRO 1. Espécies arbóreas identificadas na Trilha Curumim.

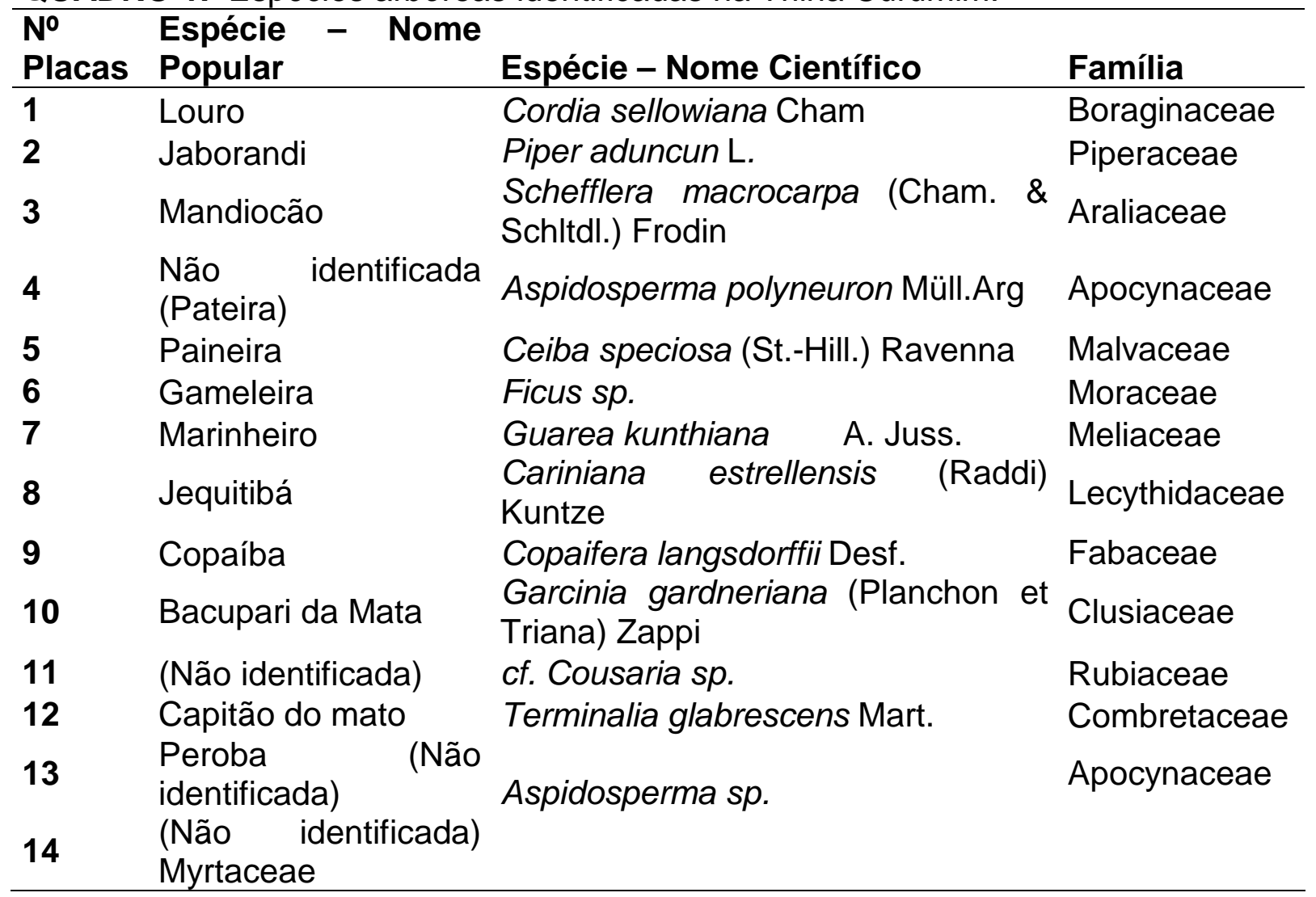

Fonte: Arquivo pessoal. 
QUADRO 2. Espécies arbóreas identificadas na Trilha Ver o Rio.

\begin{tabular}{|c|c|c|c|}
\hline № Placas & $\begin{array}{l}\text { Espécie - Nome } \\
\text { Popular }\end{array}$ & Espécie - Nome Científico & Família \\
\hline 1 & $\begin{array}{l}\text { Mirtha/Eugenia } \\
\text { (Não identificada }\end{array}$ & & \\
\hline 2 & Mandiocão & $\begin{array}{l}\text { Schefflera macrocarpa (Cham. \& Schltdl.) } \\
\text { Frodin }\end{array}$ & Araliaceae \\
\hline 3 & Pindaíba & Xylopia emarginata Mart. & Annonaceae \\
\hline 4 & Carvoeiro & $\begin{array}{l}\text { Tachigali vulgaris L.F. Gomes da Silva \& H.C. } \\
\text { Lima }\end{array}$ & Fabaceae \\
\hline 5 & Cega Machado & Physocalymma scaberrimum Pohl & Lythraceae \\
\hline 6 & Marmelo & Alibertia edulis Rich. & Rubiaceae \\
\hline 7 & Milho Cozido & Hirtella sp. / Licania indurata Pilger & Chrysobalanaceae \\
\hline 8 & Jerivá & Syagrus romanzoffiana (Mart.) Becc. & Arecaceae \\
\hline 9 & Sobre & Emmotum nitens & Icacinaceae \\
\hline 10 & Pau Pombo & Tapirira guianensis Aubl. & Anacardiaceae \\
\hline 6 & Marmelo & Alibertia edulis Rich. & Rubiaceae \\
\hline 11 & Murici do Mato & Byrsonima sericea DC. & Malpighiaceae \\
\hline 12 & Caju & Anacardium sp. & \\
\hline 13 & Sucupira & Pterodon emarginatus Vogel & Fabaceae \\
\hline 14 & Jequitibá & Cariniana estrellensis (Raddi) Kuntze & Lecythidaceae \\
\hline 15 & Canela de velho & Aspidosperma sp. & Apocynaceae \\
\hline 16 & Copaíba & Copaifera langsdorffii Desf. & Fabaceae \\
\hline 17 & $\begin{array}{ll}\text { Escova } & \text { de } \\
\text { macaco } & \end{array}$ & Apeiba tibourbou Aubl. & Malvaceae \\
\hline 18 & $\begin{array}{l}\text { Não identificada } \\
\text { (troco amarelo) }\end{array}$ & & \\
\hline 19 & Jequitibá & Cariniana estrellensis (Raddi) Kuntze & Lecythidaceae \\
\hline 20 & Araça & Psidium sp. & Myrtaceae \\
\hline 21 & Garapa & Apuleia leiocarpa (Vogel) J.F.Macbr. & Fabaceae \\
\hline 22 & Mamica de porca & Zanthoxylum rhoifolium Lam. & Rutaceae \\
\hline 23 & Farinha seca & Albizia hasslerii (Chod.) Burkart. & Fabaceae \\
\hline 24 & Embaúba & Cecropia pachystachya Trec. & Urticaceae \\
\hline 25 & Assapeixe & Vernonia polysphaera Baker & Asteraceae \\
\hline 26 & Sangra d'água & Croton urucurana Baill. & Euphorbiacae \\
\hline $\begin{array}{l}27 \\
28\end{array}$ & $\begin{array}{l}\text { Copaíba } \\
\text { Myrthaceae }\end{array}$ & Copaifera langsdorffii Desf & Fabaceae \\
\hline 29 & Jaborandi & Piper aduncun $\mathrm{L}$. & Piperaceae \\
\hline 30 & Nectandra & Nectandra sp. & Lauraceae \\
\hline 31 & Louro & Cordia sellowiana Cham. & Boraginaceae \\
\hline 32 & Mutamba & Guazuma ulmifolia Lam. & Malvaceae \\
\hline 33 & Jenipapo & Genipa americana L. & Rubiaceae \\
\hline 34 & Jatobá & Hymenaea courbaril L. & Fabaceae \\
\hline 35 & Baru & Dipteryx alata Vogel. & Fabaceae \\
\hline 36 & Goiaba & Psidium guajava $\mathrm{L}$. & Myrtaceae \\
\hline 37 & Gameleira & Ficus $s p$ & Moraceae \\
\hline 38 & Urucum & Bixa orellana L. & Bixaceae \\
\hline 39 & Ingá & Inga edulis Mart. & Fabaceae \\
\hline 40 & Ingá de metro & Inga vera Willd & Fabaceae \\
\hline Sem Placa & Buriti & Mauritia flexuosa Mart. & Arecaceae \\
\hline 42 & Aroeira & Myracrodruon urundeuva Allemão & Anacardiaceae \\
\hline 43 & Pombeiro & Tapirira guianensis Aubl. & Anacardiaceae \\
\hline 44 & Paineira & Myracrodruon urundeuva Allemão & Anacardiaceae \\
\hline
\end{tabular}


QUADRO 3. Espécies arbóreas identificadas no MDR

\begin{tabular}{llll}
\hline No & Espécie - Nome & & \\
Placas & Popular & Espécie - Nome Científico & Família \\
\hline 0 & Embaúba & Cecropia pachystachya Trec. & Urticaceae \\
1 & Baru & Dipteryx alata Vogel. & Fabaceae \\
2 & Jenipapo & Genipa americana L. & Rubiaceae \\
3 & Ingá Cilindrica & Inga cylindrica Mart. & Fabaceae \\
4 & Jacarandá/Carola & Jacaranda cuspidifolia Mart. & Bignoniaceae \\
5 & Pau ferro & Poincianella férrea Mart. & Fabaceae \\
6 & Jacaré & Piptadenia gonoacantha (Mart.) J.F. Macbr & Fabaceae \\
7 & Jatobá do Cerrado & Hymenaea stigonocarpa Mart. & Fabaceae \\
8 & Gonçalo-alves & Astronium fraxinifolium Schott & Anacardiaceae \\
9 & Mangaba & Hancornia speciosa Gomes & Apocynaceae \\
10 & Pequi & Caryocar brasiliense Camb. & Caryocaraceae \\
11 & Ipê & Handroanthus sp. & Bignoniaceae \\
12 & Angico-vermelho & Anadenanthera macrocarpa (Benth.) Brenan & Fabaceae \\
13 & Cagaita & Eugenia desynterica DC. & Myrtaceae \\
14 & Jacarandá Mimoso & Jacaranda cuspidifolia Mart. & Bignoniaceae \\
15 & Lobeira & Solanum grandiflorum Ruiz \& Pav. & Solanaceae \\
16 & Jatobá da Mata & Hymenaea courbaril L. & Fabaceae \\
17 & Sucupira & Pterodon emarginatus Vogel & Fabaceae \\
18 & Tento & Ormosia arbórea (Vell.) Harms & Fabaceae \\
19 & Copaíba & Copaifera langsdorffii Desf. & Fabaceae \\
\hline
\end{tabular}

Fonte: Arquivo pessoal.

As espécies mais abundantes em todo levantamento foram da família Fabaceae do gênero Inga, e a família Apocynaceae do gênero Aspidosperma. No levantamento florístico foram identificados um total de 60 espécies, sendo quatro indivíduos não identificados, e 51 gêneros, representados em 29 famílias.

As famílias que apresentaram maior número de indivíduos foram: Fabaceae (14), Myrtaceae (06), e Anacardiaceae (04). Essas três famílias correspondem a $82,75 \%$ das espécies identificadas, enquanto que as outras 11 famílias dividem os $17,25 \%$ restantes (Figura 1 ).

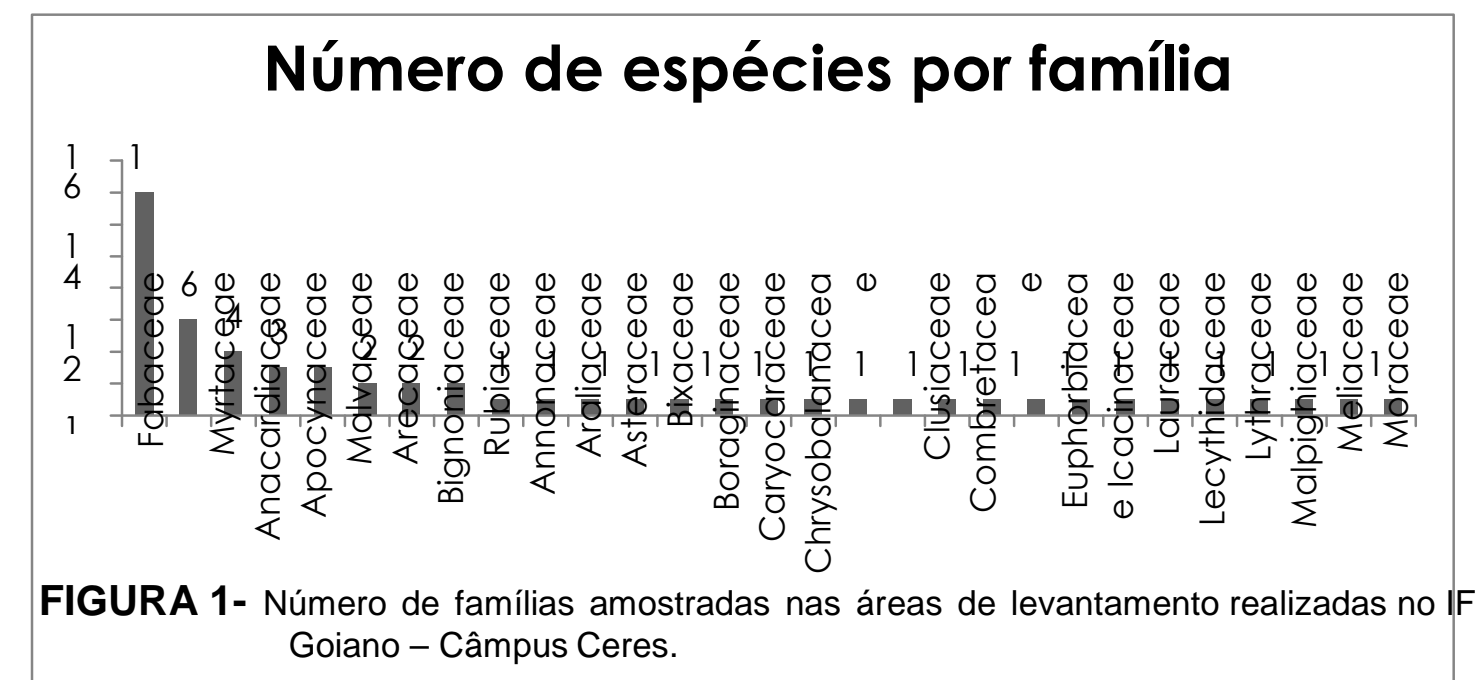


A família Fabaceae foi a mais representativa em todo levantamento e amplamente distribuída pela Trilha Ver o Rio e pelo MDR. Estes resultados têm sido encontrados em outros trabalhos florísticos em fitofisionomias de mata ciliar do Brasil Central (VAN DEN BERG \& OLIVEIRA-FILHO, 2000; MEYER et al., 2004; AZEVEDO et al., 2008) demonstrando a grande distribuição e poder adaptativo desta família a diversos tipos de solo e clima.

As Fabaceae desempenham importante papel ecológico em ecossistemas ciliares, e a presença nesse levantamento das Trilhas Ecológicas do IF Goiano Câmpus Ceres, demonstra que a comunidade vegetal atual, não foge ao padrão característico das florestas ciliares do Cerrado Central. A abundância expressiva e a ampla distribuição da família Fabaceae, se deve pela capacidade de fixação do nitrogênio atmosférico, favorecendo o processo de sucessão e o surgimento de espécies mais exigentes, apresentando potencial para implantação como facilitadora da sucessão (CARPANEZZI, 2005) e, portanto, tem importante papel na recuperação vegetacional dessas áreas antropizadas no IF Goiano - Câmpus Ceres.

Foi observada em campo, a existência de grande número de clareiras e de irregularidades no dossel da floresta sugerindo, de acordo com CORAIOLA \& NETTO (2003), que as clareiras forneceram sítios para as espécies de crescimento rápido, como as pioneiras, consideradas prováveis "oportunistas de clareira" que ocupam rapidamente as aberturas naturais. O que leva a acreditar que as espécies pioneiras encontraram nestes ambientes as condições favoráveis para seu estabelecimento e desenvolvimento. Os fragmentos estudados encontram-se com leve perturbação em decorrência do processo de antropização ao longo dos anos.

\section{CONCLUSÃO}

Dentre as espécies identificadas no levantamento florístico das Trilhas Interpretativas Curumim e Ver o Rio dentro da Área de Preservação Permanente do IF Goiano - Câmpus Ceres, as mais abundantes foram a Fabaceae do gênero Ingá, e a Apocynaceae do gênero Aspidosperma com maior predominância das famílias Fabaceae (14 indivíduos), Myrtaceae (06 indivíduos), e Anacardiaceae (04 indivíduos).

As Trilhas Ecológicas do Instituto Federal Goiano - Câmpus Ceres possuem um grande papel como instrumento de Educação Ambiental, desde a sua criação, tanto para o Instituto, como para a cidade de Ceres e das regiões vizinhas. No entanto, faz-se necessário uma reestruturação da trilha com a execução de curso de Capacitação dos Guias, fazendo uso dos resultados dessa pesquisa.

\section{REFERÊNCIAS}

AQUINO, F. G.; OLIVEIRA, M. C.; RIBEIRO, J. F.; PASSOS F. B. Módulos para recuperação de cerrado com espécies nativas de uso múltiplo. Planaltina, DF: Embrapa Cerrados, 2009.

AZEVEDO, I. F. P.; RODRIGUES, P. M. S.; MENINO, G. C. O.; VELOSO, M. D. M.; NUNES, Y. R. F.; FERNANDES, G. W. Composição Florística da Comunidade Arbórea de um trecho da mata ciliar do Rio Pandeiros, Norte de Minas. In: SIMPOSIO NACIONAL CERRADO, 9, 2008, Brasília. Anais. Brasília: Parla Mundi, 2008.

BARROSO, G. M.; PEIXOTO, A. L.; COSTA, C. G.; ICHASO, C. L. F.; GUIMARÃES, 
E. F. \& LIMA, H. C. Sistemática das angiospermas do Brasil. V.2. UFV, Viçosa, 1991.

CAMPANHA, L. F. P. \& SILVA P. O. R. Trilhas ecológicas como recurso de educação ambiental. Centro de Ciências Biológicas. Universidade Estadual de Londrina-PR, 2013.

CAMPOS, R. F. \& FILLETO, F. Análise do perfil, da percepção ambiental e da qualidade da experiência dos visitantes da Serra do Cipó (MG). Revista Brasileira de Ecoturismo, v. 4, p. 69-94, 2011.

CARDOSO, E.; MORENO, M. I. C.; BRUNA, E. M.; VASCONCELOS, H. L. Mudanças fitofisionômicas do cerrado: 18 anos de sucessão ecológica na estação ecológica do Panga, Uberlândia - MG. Uberlândia. Caminhos de Geografia. v. 10. n. 32, 2009.

CARPANEZZI, A. A. Fundamentos para a reabilitação de ecossistemas florestais. In: GALVÃO, A. P. M.; PORFÍRIO-DA-SILVA, V. (Orgs.) Restauração Florestal: Fundamentos e Estudos de Caso. Colombo: EMBRAPA/Florestas, p. 27- 45, 2005.

CORAIOLA, M. \& NETTO, S. P. Análise da Estrutura Horizontal e uma Floresta Estacional Semidecidual localizada no Município de Cássia - MG. Revista Acadêmica: ciências agrárias e ambientais, São José dos Pinhais, v. 1, n. 2, p. 11-19, 2003.

CUBA, M. A. Educação Ambiental nas Escolas. Revista de Educação, Cultura e Comunicação Social da FATEA, v. 1, n. 2, p. 23-31, jul./dez. 2010. Disponível em: http://www.fatea.br/seer/index.php/eccom/article/view/403. Acesso em: 15/10/2014.

DURIGAN, G.; NISHIKAWA, D. L. L.; ROCHA, E.; SILVEIRA, E. R.; PULITANO, F. M.; REGALADO, L. B.; CARVALHAES, M. A.; PARANAGUÁ, P. A.; RANIERI, V. E. L. Caracterização de dois estratos da vegetação em uma área de cerrado no município de Brotas, SP, Brasil. Acta Botânica Brasílica, v.16, n.3, p.251-262, 2002.

FILGUEIRAS, T. S.; NOGUEIRA, P. E.; BROCHADO, A. L. \& GUALA II, G. F. Caminhamento: um método expedito para levantamentos florísticos qualitativos. Cadernos de Geociências 12: 39-43, 1994.

LORENZI, H. Árvores brasileiras: manual de identificação e cultivo de plantas arbóreas nativas do Brasil. Nova Odessa, SP: Editora Plantarum, 1992.

LORENZI, H. Árvores brasileiras: manual de identificação e cultivo de plantas arbóreas do Brasil. Instituto Plantarum de Estudos da Flora, v. 2, 1998.

LORENZI, H. Árvores brasileiras: manual de identificação e cultivo de plantas arbóreas nativas do Brasil. Nova Odessa: Instituto Plantarum, v. 3, 2009. 
MENGHINI, F. B. As trilhas interpretativas como recurso pedagógico. Dissertação (Mestrado) - Universidade do Vale do Itajaí, 2005.

MEYER, S. T.; SILVA, A. F.; MARCO JUNIOR, P.; MEIRA NETO, J. A. A. Composição Florística da Vegetação arbórea de um trecho de floresta de galeria do Parque Estadual do Rola-Moça na Região Metropolitana de Belo Horizonte, MG, Brasil. Acta Botânica Brasílica, Brasília, v. 18, n. 4, p. 701- 709, 2004.

OLIVEIRA-FILHO, A. T. \& RATTER, J. A. Vegetation physiognomies and woody flora of the Cerrado biome. In: OLIVEIRA, P. S.; MARQUIS, R. J. (Eds.) The cerrados of Brazil: ecology and natural history of a neotropical savanna. New York: Columbia University, Columbia University Press, p. 91- 120, 2002.

RESENDE, N. F. Cerrado: ecologia, biodiversidade e preservação. Revista Brasileira de Educação e Cultura. São Gotardo, n. VI, p. 81-90, jul./dez. 2012.

RIBEIRO, J. F. \& WALTER, B. M. T. As principais fitofisionomias do Bioma Cerrado. In: SANO, S. M.; ALMEIDA, S. P; RIBEIRO, J. F. Cerrado: Ecologia e Flora. v.1 . Planaltina: Embrapa Cerrados, p. 406, 2008.

SILVA JUNIOR, M. C. 100 Árvores do cerrado: guia de campo. Brasília: Ed. Redes de sementes do cerrado, 2005.

SILVA JUNIOR, M. C. \& PEREIRA, B. A. S. + 100 árvores do cerrado Matas de galeria: guia de campo. Brasília, DF: Rede de Sementes do Cerrado, 2009.

SILVA, J. M. C. \& SANTOS, M. P. D. A importância relativa dos processos biogeográficos na formação da avifauna do Cerrado e de outros biomas brasileiros, p. 219-233, 2005. In: SCARIOT, A. O.; SILVA, J. C. S.; FELFILI, J. M. (orgs.). Biodiversidade: Ecologia e Conservação do Cerrado. Brasília: Ministério do Meio Ambiente MMA-PROBIO.

VAN DEN BERG, E. \& OLIVEIRA FILHO, A. T. Composição florística e fitossociologia de uma Floresta Estacional Semidecidual Montana em Itutinga, MG, e comparação com outras áreas. Revista Brasileira de Botânica, São Paulo, v. 22, n. 3, p. 231-253, 2000. 